\title{
INFLUÊNCIA DE DIFERENTES SOLUÇÕES DE PRÉ-DIPPING NA POPULAÇÃO MICROBIANA DOS TETOS DE VACAS LEITEIRAS CRIADAS A PASTO
}

\author{
Mateus Monteiro Dutra ${ }^{1}$, Gustavo Henrique Marques Araújo ${ }^{1}$, Roberta Reis Silva ${ }^{1}$, Aline Sousa Camargos ${ }^{3}$ \\ ${ }^{1}$ Universidade Federal de Goiânia - UFG, Departamento de Medicina Veterinária, Jataí, GO. ${ }^{2}$ Instituto Federal Goiano - \\ IFG, Departamento de Zootecnia, Morrinhos, GO. E-mail: samvetembrioes@hotmail.com
}

\section{RESUMO}

A mastite é uma enfermidade que causa grandes prejuízos na pecuária leiteira, diminuindo a produção e a qualidade do leite, aumentando os custos com medicamentos e o descarte precoce dos animais. Uma da forma de diminuir a ocorrência dessa enfermidade e utilizar o pré-dipping, uma prática de manejo realizada antes da ordenha onde os tetos dos animais são imersos em soluções desinfetantes com o objetivo de diminuir a carga microbiana e, assim, impedir que o mesmo seja infectado por qualquer agente microbiano durante a ordenha. Este trabalho teve como objetivo contabilizar a quantidade de microrganismos antes e após a realização do pré-dipping, onde de maneira geral, com exceção do SCN que apresentou aumento da população microbiana, todos os microrganismos diminuíram a sua população após a higienização do teto com diferentes produtos. $O$ ácido láctico foi o que mais conseguiu diminuir a população de Pseudomonas ssp., o iodo a população de coliforme, e o cloro foi o que apresentou menor crescimento da população de SCN.

Palavras-chave: UFC; bactérias; higienização pré-ordenha.

\section{INFLUENCE OF DIFFERENT PRE-DIPPING SOLUTIONS IN THE MICROBIAL POPULATION OF EXTENSIVE DAIRY CROPS}

\begin{abstract}
Mastitis is a disease that causes great losses in dairy farming, decreasing milk production and quality, increasing drug costs and the early disposal of animals. One of the way to reduce the occurrence of this disease and to use pre-dipping, a management practice performed before milking where the animals' ceilings are immersed in disinfectant solutions in order to reduce the microbial load and thus prevent the same Infected with any microbial agent during milking. The objective of this work was to account for the amount of microorganisms before and after the pre-dipping, in which, in general, with the exception of the SNA that presented an increase in the microbial population, all microorganisms decreased their population after the hygiene of the ceiling with different products. Lactic acid was the one that most managed to decrease the population of Pseudomonas ssp., The iodine the coliform population, and chlorine was the one that presented smaller growth of the population of SNA.
\end{abstract}

Keywords: UFC; bacteria; pre-milking hygiene.

\section{INTRODUÇÃO}

O Brasil é um país que merece destaque na bovinocultura leiteira, gerando uma produção de 35 bilhões de litros no ano de 2015, ocupando a sexta colocação entre os produtores de leite do mundo, ficando atrás somente da União Europeia, Estados Unidos, Índia, China e Rússia. Goiás, no Brasil, é quarto colocado entre os estados produtores de leite, responsável por $10,1 \%$ da produção nacional. Em 2015, o preço médio nacional foi $\mathrm{R} \$ 0,99$ por litro, gerando um valor de produção de $\mathrm{R} \$ 34,71$ bilhões (IBGE, 2016).

A pecuária leiteria nacional encontra-se em constante evolução, porém, existem alguns fatores que podem interferir no desenvolvimento dessa atividade, dentre eles encontra-se a mastite, a principal doença responsável pelas maiores perdas econômicas da atividade. Esta enfermidade é uma resposta inflamatória da 
glândula mamária frente a algum agente infeccioso ou não presente no úbere. Pode ainda, interferir na eficiência da produção do leite.

Como forma de apresentação da mastite tem-se a clínica e a subclínica, em que na forma clínica da doença o animal apresenta alterações visuais no leite como a presença de grumos, sinais de inflação da glândula mamaria, e dependendo da gravidade do agente, sinais sistêmicos graves que podem levar os animais a óbito. Já na forma subclínica não se observa nenhum sinal clínico no animal e nenhuma alteração visual do leite, o que acontece e um aumento das células somáticas no leite desses animais. Essa forma da doença é a principal responsável pelos prejuízos econômicos causados, diminuindo a produção de leite por animal, impactando na qualidade do produto, 0 qual, consequentemente, vai perder valor na indústria de alimentos.

Produtores utilizam de diferentes ferramentas com o objetivo de prevenir essa enfermidade, visando diminuir os prejuízos. Umas dessas alternativas de prevenção é a realização de uma antissepsia prévia do teto antes da ordenha, conhecida como o pré-dipping. Esta ferramenta consiste na aplicação de um antisséptico antes da ordenha, com o objetivo de diminuir a carga bacteriana presente no teto do animal ao chegar na ordenha. Atualmente existem inúmeras formulações de pré-dipping no mercado, com diferentes princípios ativos e concentrações.

Neste contexto, este estudo teve por objetivo avaliar a quantidade microrganismos nos tetos de vacas submetidas à diferentes princípios ativos na solução de pré-dipping.

\section{MATERIAL E MÉTODOS}

$O$ experimento foi realizado na Fazenda São Caetano, localizada no município de
Morrinhos - GO, às margens da GO-213, rodovia que liga as cidades de Morrinhos - $\mathrm{GO}$ e Caldas Novas - GO, latitude de $48^{\circ} 57^{\prime} 29^{\prime \prime}$ oeste, longitude $17^{\circ} 41^{\prime} 03^{\prime \prime}$ sul, altitude de 771 metros. A propriedade tem como principal sistema de produção a criação de gado leiteiro a pasto irrigado por pivô central e conta com uma produção diária de aproximadamente $13 \mathrm{mil}$ litros de leite.

No trabalho foram utilizados 7 animais da raça Girolando, variando entre dois a cinco anos, pesando cerca 450 a $500 \mathrm{~kg}$ de peso corporal, de diferentes graus de sangue, com os 4 tetos funcionais, escolhidos aleatoriamente entre o rebanho. Para se proceder com a identificação dos animais, amarrou-se cordas específicas na região da quartela, para facilitar a identificação dos mesmos na linha de ordenha.

Para avaliar a eficiência dos produtos testados procedeu-se com a coleta de amostras dos tetos com o auxílio de suabs estéreis de transporte, com meio de cultura Stuart. As amostras foram coletadas pelo mesmo manipulador em todos animais, realizado nos quatro tetos de cada animal, em quatro dias consecutivos $(9,10,11$ e 12 de dezembro de 2016), em dois momentos (primeiro momento: antes do pré-dipping; e, segundo: após o prédipping) de acordo com que os animais chegavam na linha de ordenha.

Foram testados a eficiência de três produtos utilizados para o pré-dipping de diferentes princípios ativos: a base de iodo a $0,25 \%$, cloro $14 \mathrm{ppm}$ e ácido láctico $2,0 \%$. Foi utilizado a água como pré-dipping controle. Cada dia, um teto recebeu um tratamento diferente de maneira que dentro dos quatro dias, cada teto foi testado com os quatro produtos, como demonstra a Figura 1. 
Figura 1. Esquema de tratamento pelos tetos durante quatro dias, com a utilização de quatro produtos diferentes.

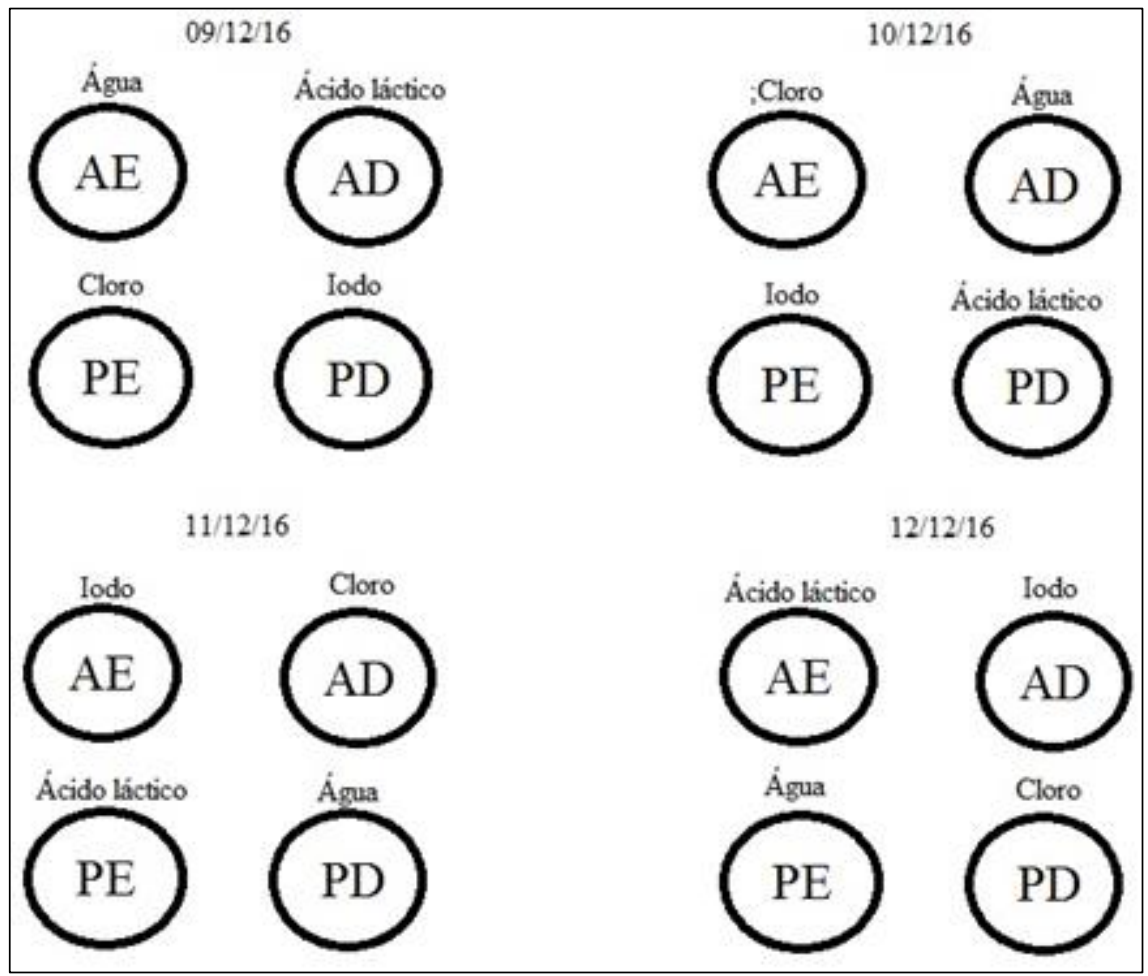

O primeiro momento de coleta aconteceu imediatamente após os animais chegarem na linha de ordenha, posteriormente era realizado a aplicação dos produtos imergindo os tetos na solução. Após 30 segundos, tempo de ação dos produtos estipulados pelo fabricante, os tetos foram enxugados com papel toalha descartável respeitando as condições de higiene. Com os tetos secos foram coletadas as amostras do segundo momentos. Logo após a coleta, as mesmas eram identificadas e armazenadas em geladeira a $5 \stackrel{\circ}{ } \mathrm{C}$.

Como padrão de coleta, eram realizados movimentos verticais ao longo do teto, circulares na extremidade distal e a ponta do teto (Figura 2).

Figura 2. Movimentos realizados como padrão de coleta. A) movimentos verticais ao longo do teto; B) circulares na extremidade distal e ao seu redor; C) ponta do teto.

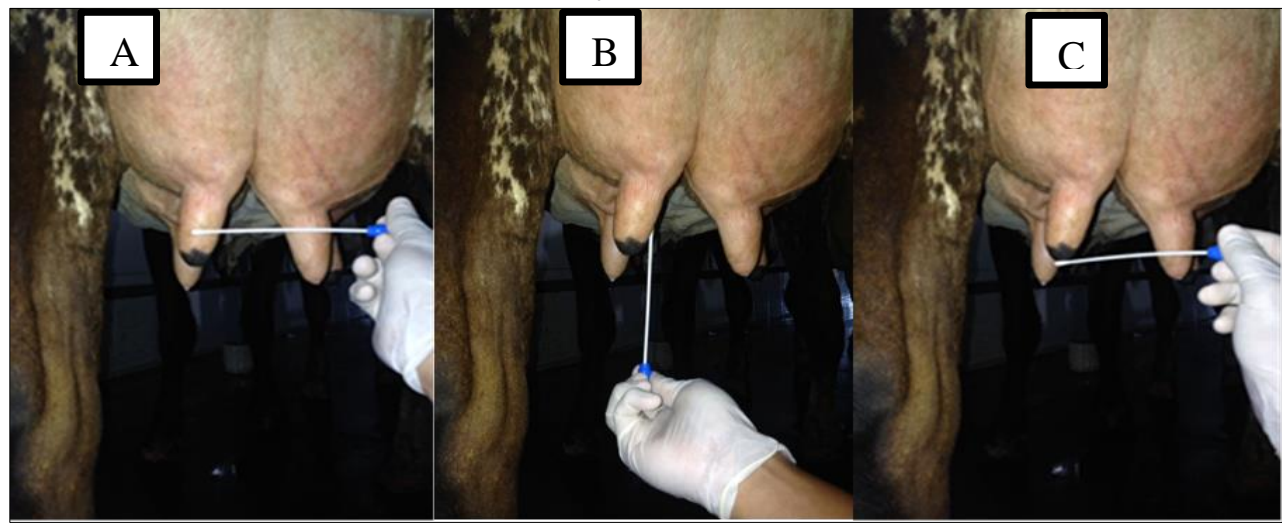

Ao final dos quatro dias de coleta as amostras foram encaminhadas ao laboratório onde foi realizado a cultura microbiológica. Os suabs foram mantidos refrigerados até o momento da cultura, e então estes foram semeados em $1 / 2$ da placa de ágar sangue e em
$1 / 2$ da placa de ágar MacConkey. As placas foram incubadas a $37^{\circ} \mathrm{C}$ por 48 horas. Isolados que cresceram na placa de ágar MacConkey foram submetidos aos testes de citrato, MIO (Motilidade, indol e lisina) e TSI (MEIO TRÍPLICE AÇUCAR FERRO). Streptococcus spp. e 
Staphylococcus spp. foram diferenciados através do teste de catalase. Colônias catalase positiva foram testadas para os testes de Manitol e Coagulase. Colônias catalase negativa foram testados para Christie, Atkins, Much-Peterson (CAMP), e reações de esculina, e bilesculina. A identificação microbiológica final foi feita através da combinação de testes bioquímicos, características em gram e a morfologia da colônia. Após a identificação a nível de gênero, todos os isolados foram congelados a $20 \% \mathrm{em}$ solução de glicerina e estocadas a $-80^{\circ} \mathrm{C}$ para futuras análises.

Como modelo estatístico foi avaliado usando análise de variância pelo procedimento MIXED do SAS, sendo quadrado latino o desenho e teto a unidade experimental. Para analisar frequência (porcentagem) na qual os microrganismos estudados estão presentes ou não na superfície dos tetos.

\section{RESULTADOS E DISCUSSÃO}

Foram encontrados nos swabs dos tetos dos animais os seguintes agentes: Bacillus spp, Streptococcus uberis, Staphylococcus coagulase negativo (SCN), Staphylococcus aureus, Pseudomonas e Coliformes: Escherichia coli, Klebsiella ssp, Proteus ssp e Enterobacter ssp. Para contabilizar esses agentes foram estabelecidos pelo laboratório em que foi realizado a cultura microbriana três escore padrões, como demonstra o quadro abaixo:

Quadro 1. Escore padrão utilizado para contabilizar agentes microbianos.

\begin{tabular}{|c|c|}
\hline \multicolumn{2}{|c|}{ Quantidade } \\
\hline $1=1$ a 10 UFC & Pequena \\
\hline $2=11$ a 100 UFC & Moderada \\
\hline $3=>100$ UFC & Abundante \\
\hline
\end{tabular}

A contagem das UFC foi dada em dois momentos, através dos suabs realizados antes da pré-higienização e após a pré-higienização, os resultados tabulados são mostrados no anexo $1 \mathrm{e}$ 2. A partir desses dados observamos que a presença de microrganismos decresce em quase todos os agentes com exceção significante do SCN após a pré-higienização independente do princípio utilizado (Tabela 1).

Tabela 1. Resultados das avaliações da frequência de contaminação de tetos de vacas leiteiras por microrganismos durante higienização na pré-ordenha.

\section{Microorganismo, $\%$ (casos/obs)}

Tempo

\begin{tabular}{ccc}
\hline Pré-higienização & Pós-higienização & \\
\hline $100 \%$ & $81,3 \%$ & \\
$(112 / 112)$ & $(91 / 112)$ & 0,97 \\
$23,2 \%$ & $25 \%$ & \\
$(26 / 112)$ & $(28 / 112)$ & 0,76 \\
$14,3 \%$ & $7,1 \%$ & \\
$(16 / 112)$ & $(8 / 112)$ & 0,09 \\
$42,9 \%$ & $54,5 \%$ & \\
$(48 / 112)$ & $(61 / 112)$ & 0,08 \\
$99,1 \%$ & $83,0 \%$ & \\
$(111 / 112)$ & $(94 / 112)$ & 0,004 \\
\hline
\end{tabular}

Pseudomonas ssp

Coliformes $^{1}$

Bacillus ssp

S. uberis

SCN

1Coliformes: E. coli, Klebsiella ssp, Proteus ssp e Enterobacter ssp.
O Staphylococcus coagulase negativo ( $\mathrm{SCN}$ ) foi o agente que teve aumento significativo na frequência de isolamento após a realização do pré-dipping, que mostrou uma tendência estatística $(p=0,08)$, diferente dos outros que diminuíram ou mantiveram a frequência de isolamento observada anteriormente à prática. Pankey et al. (1987) realizou um experimento no 
qual separou animais em dois lotes onde um desses recebia uma higienização previa antes da ordenha com pre-dipping a base de iodo, e outro não servindo de controle. Neste trabalho o autor e colaboradores observaram que o pré-dipping reduziu aproximadamente $54 \%$ a taxa de infecção intramamária com os principais patógenos causadores de mastite aproximadamente, com exceção das infecções de úbere causadas pelo com SCN, que não foram controladas pela préhigienização.

Na Fazenda São Caetano, propriedade em que foi realizado o experimento, de acordo com cultura antimicrobiana realizada em todos os animais em lactação na propriedade no mês do experimento, O SCN foi isolado em $13,48 \%$ dos animais e o mesmo vem se apresentando como maior causador de mastite ambiental da fazenda.

Não se sabe ao certo o que possa ter levado a esse aumento da população microbiana do SCN após a utilização dos pré-dipping, não se encontrou nenhuma referência na literatura justificando o acontecido. $O$ que se encontra é que em países como a Nova Zelândia e Austrália, praticamente não se realizam a prática de préhigienização, levando em conta que grande parte da produção desse pais e dada pelo sistema de criação de animais a pasto, assim como a realidade de onde foi realizado o experimento. Já na Europa, Uruguai, Argentina e Chile a prática e realizada em menos de $50 \%$ das propriedades. Pesquisadores da Nova Zelândia defendem a ideia de que se o animal chega na ordenha com o teto limpo e seco, não é necessário fazer nenhum procedimento de pré-higienização no teto desse animal, pois acreditam que molhando o teto, com qualquer princípio ativo que seja, este vai servir para espalhar a bactéria que possa estar em um ponto especifico do teto, aumentando assim os riscos desse animal vir a apresentar uma mastite (WOODCOCK, 2006).

A Tabela 2 a seguir compara os escores médios de UFC antes e depois a realização da pré higienização do teto dos animais, mostrando a variação da população microbiana utilizando a higienização pré-ordenha independentemente do princípio ativo utilizado.

Tabela 2. Resultados das avaliações da colonização de microorganismos em tetos de vacas leiteiras durante higienização na pré-ordenha.

\begin{tabular}{|c|c|c|c|c|}
\hline \multirow{2}{*}{$\begin{array}{l}\text { Microorganismo, } \\
\text { escore de UFC }\end{array}$} & \multicolumn{2}{|c|}{ Tempo } & \multirow{2}{*}{$\mathrm{EPM}^{2}$} & \multirow{2}{*}{$p$-valor } \\
\hline & Pré-higienização & Pós-higienização & & \\
\hline Coliformes $^{3}$ & 2,74 & 1,96 & 0,11 & $<0,001$ \\
\hline Bacillus ssp & 0,48 & 0,40 & 0,09 & 0,51 \\
\hline S. uberis & 0,32 & 0,13 & 0,07 & 0,05 \\
\hline S. agalactiae & 0,00 & 0,00 & - & - \\
\hline SCN & 0,85 & 1,12 & 0,11 & 0,09 \\
\hline Levedura & 0,00 & 0,00 & - & - \\
\hline S. aureus & 0,00 & 0,03 & 0,01 & 0,08 \\
\hline Pseudomonas ssp & 2,78 & 2,03 & 0,10 & $<0,001$ \\
\hline
\end{tabular}

${ }^{1}$ Escore de UFC (unidades formadoras de colônia): 0) ausência de contaminação ou contaminação não detectado (UFC = 0) 1), contaminação baixa $(1 \leq$ UFC $\leq 10)$, 2) contaminação moderada $(10<$ UFC $\leq 100)$, e 3) contaminação abundante (UFC > 100).

${ }^{2}$ Erro padrão médio.

${ }^{3}$ Coliformes: E. coli, Klebsiella ssp, Proteus ssp e Enterobacter ssp

A tabela 3 a seguir, mostra os índices médios de UFCs antes do pré-dipping, e após o pré-dipping destacado de vermelho, padronizando o erro padrão da média (EPM), e assim se observe a variação numérica da resposta dos microrganismos a cada princípio ativo usado na solução de higienização pré-ordenha. 
Tabela 3. Colonização de microrganismos em tetos de vacas leiteiras durante a pré- higienização e póshigienização na pré-ordenha

\begin{tabular}{|c|c|c|c|c|c|}
\hline \multirow{2}{*}{$\begin{array}{l}\text { Microorganismo, } \\
\text { escore de UFC }\end{array}$} & \multicolumn{3}{|c|}{ Tratamento } & & \multirow[t]{2}{*}{$\mathrm{EPM}^{2}$} \\
\hline & Água & Ác.Lac. & Cloro & lodo & \\
\hline Coliformes $^{4}$ & 2,86 & 2,68 & 2,75 & 2,68 & 0,11 \\
\hline Coliformes $^{4}$ & 2,46 & 1,86 & 1,86 & 1,64 & 0,28 \\
\hline Bacillus ssp & 0,46 & 0,64 & 0,54 & 0,29 & 0,19 \\
\hline Bacillus ssp & 0,29 & 0,46 & 0,46 & 0,39 & 0,18 \\
\hline S. uberis & 0,14 & 0,54 & 0,11 & 0,50 & 0,16 \\
\hline S. uberis & 0,21 & 0,04 & 0,11 & 0,18 & 0,10 \\
\hline SCN & 0,89 & 0,93 & 0,96 & 0,61 & 0,22 \\
\hline SCN & 1,14 & 1,18 & 1,07 & 1,07 & 0,24 \\
\hline Pseudomonas ssp & 2,82 & 2,75 & 2,82 & 2,71 & 0,11 \\
\hline Pseudomonas ssp & 2,46 & 1,71 & 1,86 & 2,07 & 0,27 \\
\hline
\end{tabular}

${ }^{1}$ Escore de UFC (unidades formadoras de colônia): 0) ausência de contaminação ou contaminação não detectado (UFC $=0)$, 1) contaminação baixa $(1 \leq$ UFC $\leq 10), 2)$ contaminação moderada $(10<$ UFC $\leq 100)$, e 3$)$ contaminação abundante (UFC > 100).

A figura 3 especifica qual dos princípios ativos foram mais eficientes em diminuir a população de microrganismos. Para reduzir a população de Pseudomonas ssp o princípio ativo mais eficiente foi o ácido lático, já os Coliformes o iodo se apresentou mais eficiente na higienização pré ordenha.

Figura 3. Princípios ativos mais eficientes em diminuir a população de Pseudomonas ssp e Coliformes.

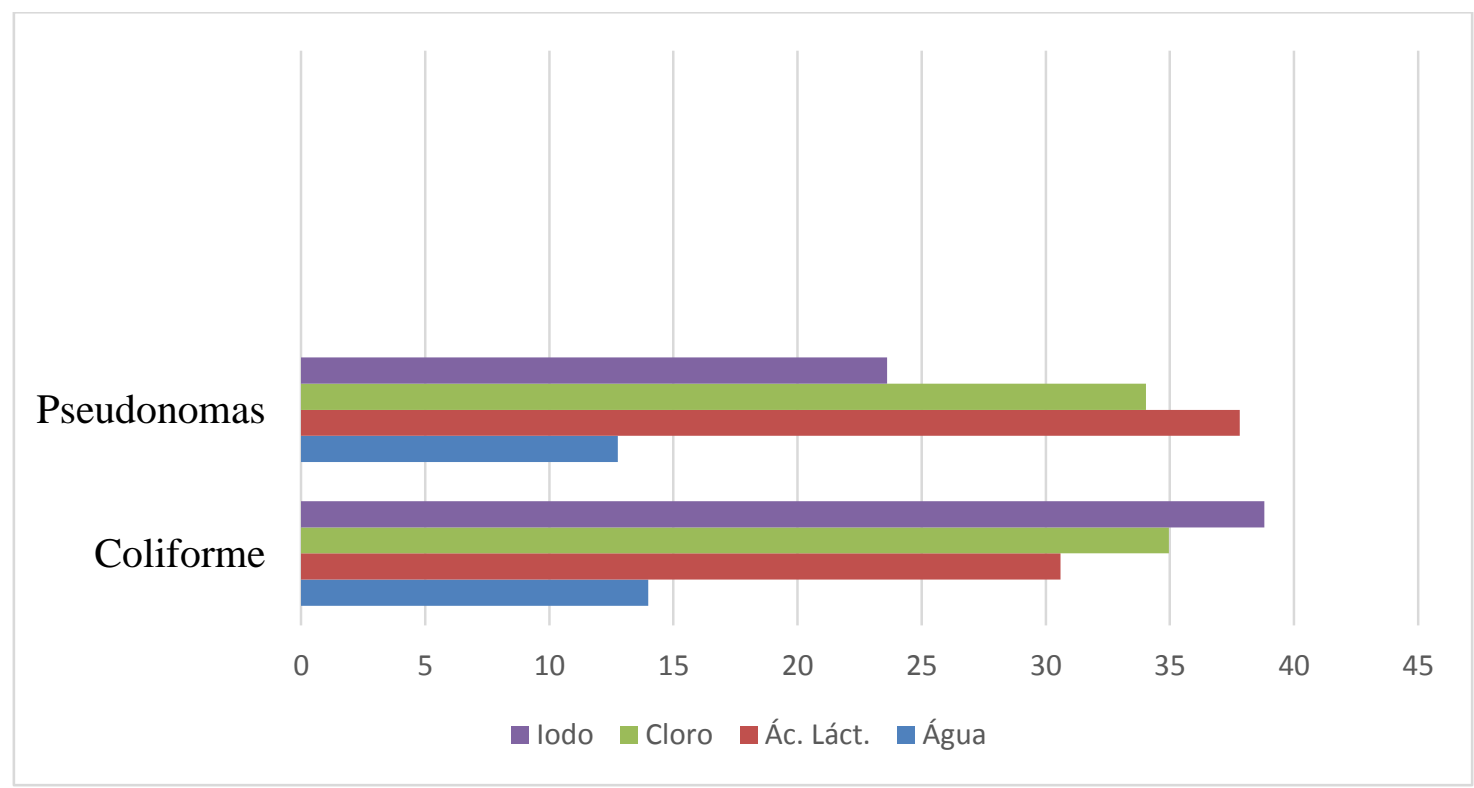


Com relação ao SCN, a figura 4 mostra que dentre os princípios ativos utilizados no pre-dipping, o cloro foi o que proporcionou menor aumento na população do microrganismo.

Figura 4. Princípio ativo que proporcionou menor aumento na população de SCN após o pré-dipping.

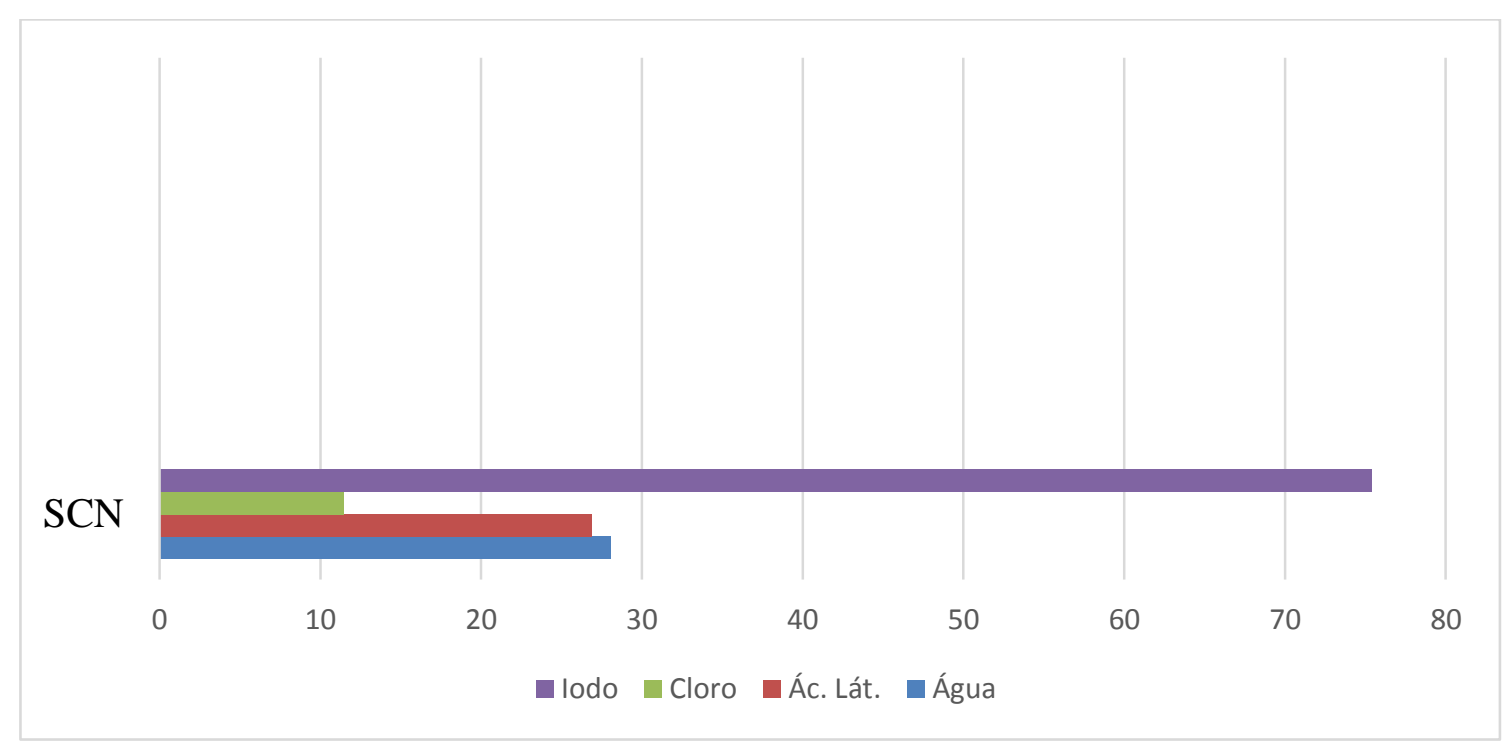

\section{CONCLUSÃO}

Conclui-se que apenas alguns microrganismos ou classes de microrganismos foram afetados pelo uso de diferentes componentes ativos na higienização pré-ordenha de tetos de vacas leiteiras, em que o ácido láctico, o cloro e o iodo diminuíram os níveis de contaminação por coliformes e Pseudomonas ssp na superfície externa dos tetos, mas o uso desses compostos não eliminou a contaminação totalmente. Os resultados ainda mostram que, de modo geral, higienização pré-ordenha da superfície externa dos tetos diminuiu a carga de microrganismos nos mesmos, porém a presença ou não de patógenos foi apenas ligeiramente alterada em relação à pré-higienização. Para SCN, a higienização pré-ordenha dos tetos contaminou e aumentou a carga de patógenos na sua superfície.

\section{REFERÊNCIAS}

IBGE. Produção da Pecuária Municipal. Rio de Janeiro: IBGE, 2016. v. 43, p. 1-49.

PANKEY, J.; WILDMAN, E. E.; DRESCHLER P. A.; Hogan. J. S. Field trial evaluation of pre-milking teat disinfection. Journal of Dairy Science, n.70, p.867-72, 1987.

https://doi.org/10.3168/jds.S0022-

\section{WOODCOCK, B. Controle de CCS na Nova} Zelândia. 2006. Disponível em: <https://www.milkpoint.com.br/seuespaco/espaco-aberto/controle-de-ccs-na-novazelandia-84676n.aspx>. Acesso em: 20 jan. 2017.

Recebido para publicação em 16/08/2017

Revisado em 13/09/2017

Aceito em 09/10/2017 